\title{
Three-phase four wire voltage controlled AC line conditioner with unity input power factor and minimised output voltage harmonics
}

\author{
Y.-K. Lo \\ C.-L. Chen, PhD
}

Indexing terms: AC line conditioner, Unity input power factor, Minimised output harmonics

\begin{abstract}
The paper presents a new high performance AC line conditioner isolating any configuration of nonlinear loads for three-phase four wire applications. The proposed conditioner is composed of a switch mode rectifier (SMR) and a ROM based sinusoidal pulse width modulation (SPWM) inverter. The three-phase half bridge type SMR operates under voltage mode control. No current sensing is required. The inverter is also a half bridge type controlled by a ROM based SPWM modulator. Preoptimised SPWM control patterns rejecting effects of DC link voltage ripples and dead times are programmed. Owing to the nature of the three-phase scheme, the voltage imbalance problem between the DC link capacitors can be lessened. High quality three-phase AC outputs can be obtained while nearly sinusoidal input currents are drawn.
\end{abstract}

\section{Introduction}

More and more industrial applications require the supply of three-phase power source to nonlinear loads. These nonlinear loads cause problems in the power distribution system, such as low power factor, high input current harmonic contents and distortion in line input voltage waveform. This will result in the degradation of the power quality supplied to other loads. Standards and recommended guidance such as IEEE-519 and IEC-555 have put limits on specified harmonics in line current owing to load nonlinearities.

Several approaches for minimising line current harmonics in three-phase, three wire systems have been proposed [1-3]. Nevertheless, in some industrial and commercial applications, power is distributed through three-phase four-wire systems. Such systems may suffer from excessive neutral currents caused by nonlinear or unbalanced loads. A four wire, current controlled active filter proposed [4] can provide harmonic neutralisation. However, by using a variable hysteresis current mode controller, undesirable harmonics are present. Sensing large load currents in a high power system is ineffective

(C) IEE, 1995

Paper 1598B (P1), first received 28th April and in revised form 16th September 1994

The authors are with the Department of Electrical Engineering, National Taiwan University, Taipei, Taiwan 10764, Republic of China

IEE Proc.-Electr. Power Appl, Vol. 142, No. 1, January 1995 due to the impractical scaling down. Also the three-phase $\mathrm{AC}$ voltages are not guaranteed to be pure sinewaves.

In this paper, a three-phase four wire AC line conditioner is presented. The block diagram of the proposed system is shown in Fig. 1. The three-phase half bridge

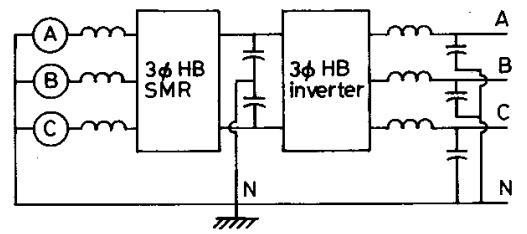

Fig. 1 Block diagram of proposed line conditioner

SMR is built by paralleling three single phase modules [5] which achieve unity input power factor with a minimum of switches and low conduction losses. The SMR is controlled under voltage mode feedback [6]. No current sensing is required. Because the current waveform reference contained in the control signal is irrelevant with the AC source voltage, input current is still a pure sinewave despite of distortion in source voltage. Two series connected capacitors provide a filtered DC voltage and energy storage. A ROM based SPWM inverter [7] converts the DC link voltage into fixed-frequency ( 50 or $60 \mathrm{~Hz}$ ) three-phase AC sources. Preoptimised SPWM control patterns compensating DC link voltage ripple $[8$, 9] and dead time degradation $[10,11]$ are stored in the proposed modulator. The possibility of excessive load current in the neutral, due to nonlinear or unbalanced loads, is prevented by the DC link capacitor tank. The neutral current at the source end is the negative sum (ideally zero) of the three-phase input currents which are forced to follow a balanced situation. Both the neutral conductor and the transformer can be protected from damage. In the following Sections, control principles, the performance simulations and laboratory experiments of the new AC line conditioner will be discussed in detail.

\section{Voltage mode control of SMR}

A $1 \phi$ half-bridge SMR is shown in Fig. 2A. In the positive half cycle of the $A C$ voltage, input current increases when $S 2$ is on and decreases when $S 2$ is off and D1 is forced to conduct. In the negative half cycle the corresponding switches are S1 and D2. By turning on and off the respective switch for a proper duration, the input current can be controlled to follow a sinusoidal waveform. An equivalent circuit for a $1 \phi$ SMR, derived by 
looking into the switching rectifier, is shown in Fig. 2B. Depending on the switching state, $v_{u}$ could be $E$ or $-E$, where $E$ is the DC voltage of the output capacitor.

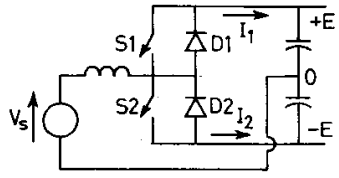

Fig. 2A IQSMR

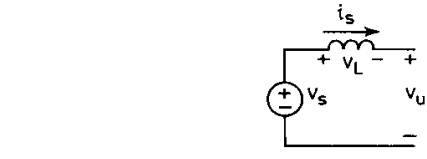

Fig. 28 Equivalent circuit

From Fig. 2B the control principles are deduced as: $v_{s}(t)=v_{L}(t)+v_{w, 1}(t)$ from Kirchhoff's voltage law, where $v_{v, 1}(t)$ is the fundamental component of $v_{u}$. Let $i_{s}(t)=I_{s} \sin \omega t$ under steady state, then $v_{L s}(t)=L_{s}$ $d i_{s}(t) / d t=\omega L_{s} I_{s} \cos \omega t$ and $v_{u, 1}(t)=v_{s}(t)-\omega L_{s} I_{s} \cos \omega t$. From the transfer characteristics of the SPWM inverter and the theorem of superposition, to produce an $\mathrm{AC}$ voltage $v_{w, 1}(t)$, the control signal has to be

$$
v_{c o n}=v_{u, 1} / E=\frac{v_{s}(t)}{E}-\frac{\omega L_{s} I_{s}}{E} \cos \omega t
$$

$I_{s}$ can be related to output voltage through a PI controller. That is $v_{\text {con }}=k_{1} v_{s}(t)-k_{2} \cos \omega t$, where $k_{1}$ is the parameter concerning the feedforward input voltage and $k_{2}$ concerning the feedback output voltage. Even when $v_{s}(t)$ is distorted, the input current still can be an ideal sinewave. The reason is that the waveform reference of input current subjects only to the cosine-term in control signal and is not affected by the source voltage. The block diagram is shown in Fig. 3.

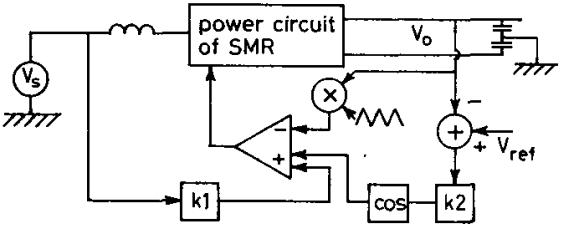

Fig. 3 Block diagram of SMR voltage-mode control

A three-phase half bridge SMR composed of three single-phase modules is shown in Fig. 4. Three sets of control signals for each phase are generated through the same mechanism except for $120^{\circ}$ phase lead or delay.

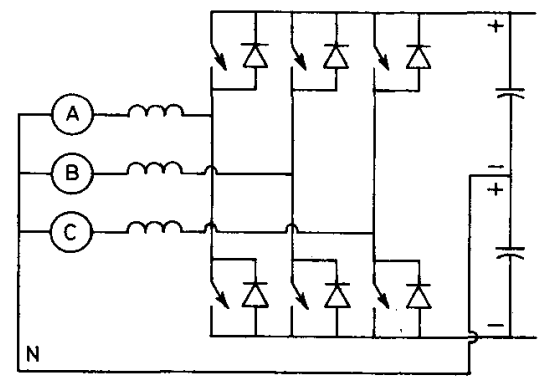

Fig. 4 Three-phase half-bridge SMR circuit
That is,

$$
\begin{aligned}
& v_{\text {con }, a}=k_{1} v_{s a}(t)-k_{2} \cos \omega t \\
& v_{\text {con, } b}=k_{1} v_{s b}(t)-k_{2} \cos \left(\omega t-120^{\circ}\right) \\
& v_{c o n, c}=k_{1} v_{s c}(t)-k_{2} \cos \left(\omega t+120^{\circ}\right)
\end{aligned}
$$

If the three-phase sources are purely sinusoidal, $v_{s a}(t)=V_{s} \sin \omega t, \quad v_{s b}(t)=V_{s} \sin \left(\omega t-120^{\circ}\right)$ and $v_{s c}(t)=$ $V_{s} \sin \left(\omega t+120^{\circ}\right)$, the cosine part in control signal of each phase can be obtained by summing the other two-phase sources. For example, $\cos \omega t=$ $[1 / \sqrt{(3)}]\left[\sin \left(\omega t-120^{\circ}\right)+\sin \left(\omega t+120^{\circ}\right)\right]$. The block diagram of generating phase A control signal is illustrated in Fig. 5.

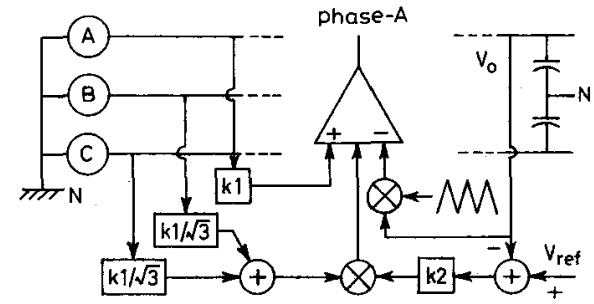

Fig. 5 Generation of phase-A control signal

\section{ROM based SPWM inverter}

Conventionally, control signals fed to the SPWM inverters are produced by electronic hardware or microprocessor. The cost and complexity of hardware implementation and online computation in the microprocessor approach are considerable. A ROM based SPWM modulator can solve the problems mentioned above. Unlike the previous works, in which the programmed contents are either digital representations of sampled sinewave heights or harmonic elimination PWM patterns with fewer notches, the proposed modulator stores the SPWM patterns computed offline in the EPROM. To program the analogue SPWM patterns into digital forms, each pulse is composed of several consecutive $1 \mathrm{~s}$ to represent its width. The duration between pulses are represented by consecutive 0 s. This digitised SPWM pattern can then be retrieved sequentially by incrementing the address counter. This modulator features the advantages of low cost, fast response, simple implementation and control. In this paper, the SPWM control signals are precalculated by computing the intersections of a sinusoidal reference wave and a triangular carrier wave with numerical method. A fixed frequency clock counts through the addresses to retrieve the stored SPWM control patterns.

With low order line frequency ripple on the DC link voltage, typically utilised SPWM techniques will produce unwanted low frequency harmonics in the inverter's output. They can be eliminated by modifying the modulation function $[8,9]$. Assuming that the DC link voltage, $V_{D C}$, is ripple free, the output of the inverter is then an $A C$ voltage modulated by a switching function with frequency spectrum as depicted in Fig. 6. Harmonics

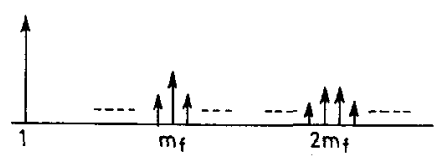

Fig. 6 Spectrum of SPWM modulation function

IEE Proc.-Electr. Power Appl., Vol. 142, No. 1, January 1995 
are centred around the multiples of the switching frequency. This AC output can be written as

$$
\begin{aligned}
V_{A C}=V_{D C} & {\left[m_{a} \sin \omega t\right.} \\
& \left.+\sum_{n+k=\text { odd }} l\left(m_{f} n \pm k\right) \sin \left(\left(m_{f} n+k\right) \omega t\right)\right]
\end{aligned}
$$

where $m_{a}$ is the amplitude modulation index and $m_{f}$ is the frequency modulation index. $l\left(m_{f} n \pm k\right)$ is the amplitude of the corresponding $\left(m_{f} n \pm k\right)$ th order harmonic. By filtering out the high-order harmonics, a fundamental $A C$ voltage $V_{D C} m_{a} \sin \omega t$ can be obtained.

Let us now consider the case in which low-order harmonic $k h(\omega t)$ is superimposed on the DC link voltage, $V_{D C}^{\prime}=V_{D C}(1+k h(\omega t))$. The modulated AC output voltage then becomes

$$
\begin{aligned}
V_{A C}^{\prime}= & V_{D C}(1+k h(\omega t))\left[m_{a} \sin \omega t\right. \\
& \left.+\sum_{n+k=\text { odd }} l\left(m_{f} n \pm k\right) \sin \left(\left(m_{f} n \pm k\right) \omega t\right)\right] \\
= & V_{A C}+V_{D C} k h(\omega t) m_{a} \sin \omega t+\cdots
\end{aligned}
$$

Undesirable low-order harmonics are produced owing to the multiplication of two low-order terms $k h(\omega t)$ and $m_{a} \sin \omega t$. By modifying the original modulation function to $m_{a} \sin \omega t / 1+k h(\omega t)$, the effects of low-order ripple can be removed.

For a bridge type inverter, a short period of time is always included in control signals between turning one switch in an inverter leg off and turning the other one on. This is referred to as 'dead time' which prevents two switches of an inverter leg from simultaneous conduction. It has been found that the dead time causes a reduction in the fundamental component of the output voltage and introduces low-order harmonics which should not be present [10]. A load current dependent compensation method [11] can eliminate the output voltage harmonic distortion due to dead time effects. The principles of the compensation techniques are summarised here. When the load current is positive, the timing of the triggering signals to the upper switch in an inverter leg coincides with the ideal control patterns. Conversely, when the load current is negative, the firing signals to the lower switch coincide with the ideal requirements. In this way the output $\mathrm{AC}$ voltage waveform is almost the same as the original SPWM control patterns. An example of

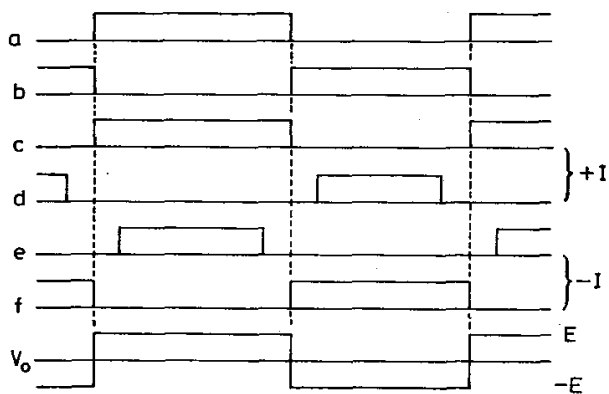

Fig. 7 Switching waveforms for dead time compensation

$\mathbf{a}=$ ideal trigering signtal for upper switch, $\mathbf{b}=$ ideal triggering signal for lower switch, $c=$ control signal for upper switch when current $>0, d=$ control signal for lower switch when current $>0, c=$ control signal for upper switch when current $<0, f=$ control signal for lower switch when current $>0, V_{0}=$ resulting AC output voltages

IEE Proc.-Electr. Power Appl, Vol. 142, No. 1, January 199 switching waveforms for dead time compensation is shown in Fig. 7. The proposed method is impossible to implement on the exiting system because it requires primary generation of control patterns for switches. However, the real time compensation can be performed on preprogrammable fixed frequency SPWM patterns.

In the proposed ROM based modulator, an optimised SPWM switching function compensating DC link voltage ripple and dead time effects can be offline calculated and preprogrammed. A fixed frequency oscillator with counters retrieves the SPWM patterns by counting through the addresses of the ROM. A reset signal is sent from the ROM to ensure a complete cycle. The schematic version of a three-phase inverter is shown in Fig. 8 and the block diagram of the proposed modulator is illustrated in Fig. 9.

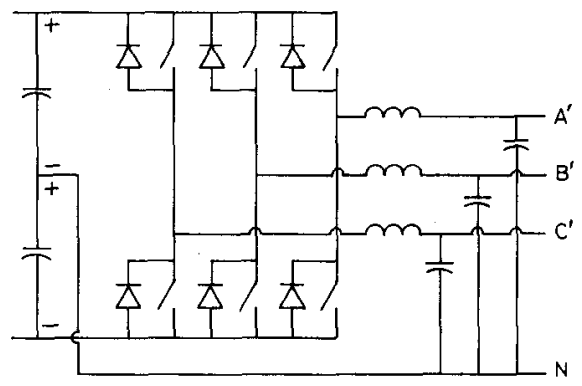

Fig. 8

Three-phase inverter

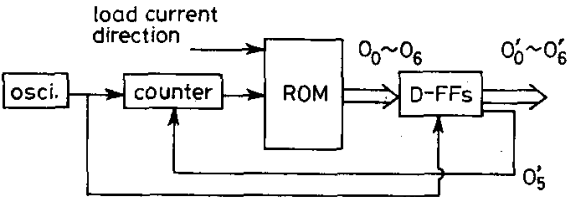

Fig. 9 Proposed ROM-based SPWM modulator

\section{Design considerations}

For the three-phase SMR, the designed issues are the input current ripple and the switching frequency. The former decides the value of the THD, and the latter concerns the frequency distribution of the harmonics. The input current ripple is a function of switching frequency, input inductance, input voltage and output voltage. Since all other three factors are set, the only controllable is the switching frequency. The switching frequency is recommended to be high above audible noise, which is about $20 \mathrm{kHz}$. Another advantage is to push the harmonics far away from source frequency. Thus the switching frequency is high and constant under the voltage feedback control. These contribute to easy filtering of switching harmonics. The allowable switching speed and switching loss of a practical switch should be taken into account. Based on the considerations above, the switching frequency can be designed by analysing Fig. 10

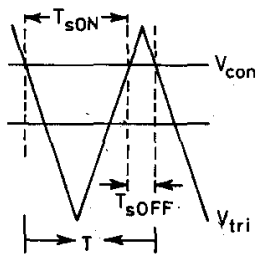

Fig. 10 Production of SPWM control signals 
Since the input current varies sinusoidally, its switching ripple varies period by period. The current ripple can be defined as the average current variations in a switching period:

$$
2 \Delta I=\left[(d I / d t)_{i m c} T_{s o N}+(d I / d t)_{\text {dec }} T_{\text {soFF }}\right]
$$

$(d I / d t)_{\text {ioc }}$ and $(d I / d t)_{\text {dec }}$ are the increasing and decreasing rates of input current. $T_{\text {soN }}$ and $T_{\text {soFF }}$ are the on time and off time of the switches, respectively. $T$ is a switching period. By specifying the maximum current ripple $r_{i} \%$ and differentiating $\Delta I$ to $\theta$, we can solve for $m_{f}$ :

$$
m_{f} \geqslant \frac{50 \pi}{I_{s} r_{i} \omega L}\left(\frac{V_{s}^{2}}{E}+\frac{V_{s}}{E} \sqrt{ }\left[\left(\omega L I_{s}\right)^{2}+V_{s}^{2}\right]+2 E\right)
$$

where $f_{1}$ is the fundamental frequency. The deduction is as follows:

$$
T=\frac{2 \pi}{\omega_{s}}=\frac{1}{f_{1} m_{f}} \quad \text { slope of } V_{t r i}= \pm \frac{1}{T / 4}= \pm \frac{4}{T}
$$

So

$$
\begin{aligned}
T_{\text {sON }} & =2\left(\frac{V_{\text {con }}}{\text { slope }}+\frac{T}{4}\right) \\
& =2\left(\frac{m_{a} \sin (\theta-\phi)}{\text { slope }}+\frac{T}{4}\right) \\
& =\frac{T}{2}\left(1+m_{a} \sin (\theta-\phi)\right) \\
T_{\text {sOFF }} & =T-T_{\text {sON }}=\frac{T}{2}\left(1-m_{a} \sin (\theta-\phi)\right)
\end{aligned}
$$

where $V_{\text {com }}=V_{s} \sin \theta-w L I_{s} \cos \theta=m_{a} \sin (\theta-\phi)$, $m_{a}=\sqrt{ }\left[V_{s}^{2}+\left(\omega L I_{s}\right)^{2}\right] / E$, and $\phi=\tan ^{-1}\left(\omega L I_{s} / V_{s}\right)$. Substituting eqns. 6 and 7 into eqn. 4 :

$$
\begin{aligned}
\Delta I= & \frac{1}{2}\left[\frac{V_{s} \sin \theta+E}{L} \frac{T}{2}\left(1+m_{a} \sin (\theta-\phi)\right)\right. \\
& \left.+\frac{E-V_{s} \sin \theta}{L} \frac{T}{2}\left(1-m_{a} \sin (\theta-\phi)\right)\right] \\
= & \frac{T}{4 L}\left[V_{s} m_{d}(\cos \phi-\cos (2 \theta-\phi))+2 E\right]
\end{aligned}
$$

By maximising $\Delta I$ wrt $\theta$, a maximum current ripple can be obtained at $\theta=180^{\circ}+\phi / 2$. The minimum $m_{f}$ thus can be calculated:

$$
\begin{gathered}
\Delta I_{\max }=\frac{T}{4 L}\left[V_{s} m_{d}(\cos \phi+1)+2 E\right] \leqslant I_{s} r \% \\
V_{s} \frac{\sqrt{\left[V_{s}^{2}+\left(\omega L I_{s}\right)^{2}\right]}}{E}\left(\frac{V_{s}}{\sqrt{ }\left[V_{s}^{2}+\left(\omega L I_{s}\right)^{2}\right.}+1\right) \\
+2 E \leqslant \frac{I_{s} r L f_{1} m_{f}}{25} \\
m_{f} \geqslant \frac{50 \pi}{I_{s} r \omega L}\left(\frac{V_{s}^{2}}{E}+\frac{V_{s}}{E} \sqrt{ }\left[V_{s}^{2}+\left(\omega L I_{s}\right)^{2}\right]+2 E\right)
\end{gathered}
$$

If $m_{f}$ is a value smaller than 333 , which means a switching frequency of $20 \mathrm{kHz}$, we can set $m_{f}$ to be 333 or higher.

For the three-phase inverter, switching frequency is set to be the same as in SMR stage. An important factor to be considered is the amplitude modulation index $m_{a}$, which is the amplitude ratio of $V_{\text {con }}$ to the $V_{t r i}$. According to analysis [12], $m_{a}$ (less than 1 in linear modulation) is also the amplitude ratio of fundamental output component to AC source voltage. To prevent too short turn on or off times near the odd multiples of $\pi / 2$ in $V_{c o n}, m_{a}$ should not be too small. In this paper, $m_{e}$ is set to be the value $V / E$ for $A C$ output to obtain the same amplitude with the source. The counting rate of the ROM based SPWM modulator should be fast enough to minimise the quantisation error. Its upper limit is the fetching speed of the ROM. It also should be noted that the required memory size is proportional to the counting rate of the oscillator. Three-phase SPWM control patterns can be programmed by delaying phase $A$ signals $2 \pi / 3$ and $4 \pi / 3$, respectively, to get patterns of phase $B$ and phase $C$.

Usually the DC link capacitors are determined by the specified voltage ripple. In the single-phase SMR, as shown in Fig. $2 a, I_{1}$ and $I_{2}$ are sinewaves modulated by SPWM pulses.

$$
\begin{aligned}
I_{1}= & I_{s} \sin \omega t \\
& \times \frac{1}{2}\left[1+m_{a} \sin (\omega t-\phi)+\text { high frequency terms }\right] \\
= & \frac{1}{4} I_{s} m_{a} \cos \phi+\frac{1}{2} I_{s} \sin \omega t \\
& +\frac{1}{4} I_{s} m_{a} \cos (2 \omega t-\phi) \\
& + \text { high frequency terms } \\
I_{2}= & I_{s} \sin \omega t \\
& \times \frac{1}{2}\left[1-m_{a} \sin (\omega t-\phi)+\text { high frequency terms }\right] \\
= & -\frac{1}{4} I_{s} m_{a} \cos \phi+\frac{1}{2} I_{s} \sin \omega t \\
& -\frac{1}{4} I_{s} m_{a} \cos (2 \omega t-\phi) \\
& + \text { high frequency terms }
\end{aligned}
$$

In the above equations of $I_{1}$ and $I_{2}, \mathrm{DC}$ components supply the load. The source current splits into two equal fundamental components. The second-order harmonic results in the voltage ripple superimposed on the DC link voltage. According to the $V-I$ characteristics of the capacitors, the required capacitance for a specified voltage ripple can be determined:

$$
\begin{aligned}
\Delta V & =\left(\text { second order harmonic of } I_{1}\right)\left(\frac{1}{2 \omega C}+\frac{1}{2 \omega C}\right) \\
& =\frac{\frac{1}{4} I_{s} m_{a}}{\omega \mathrm{C}} \quad C=\frac{I_{s} m_{a}}{4 \omega \Delta V}
\end{aligned}
$$

Bulky DC link capacitors are needed to provide filtering and energy storage. The cost, weight and size are considerable, and dynamic response slows down. In the proposed line conditioner scheme, the effect of DC link voltage ripple is compensated in the programmed SPWM control patterns. Also by taking advantage of the nature of three-phase system in which balanced threephase vectors sum up zero, the energy storage function of the capacitors becomes not so stringent. In this way, the voltage imbalance problem can be lessened.

\section{Simulations and experiments}

Simulations have been tested on a system with the following operating conditions:

Line-to-neutral source voltage $V_{s}=110 \mathrm{~V}$ (RMS), $60 \mathrm{~Hz}$.

AC side impedance $\omega L=5 \Omega$; input current ripple $r_{i} \%=10 \%$

Output power $P=3 \mathrm{~kW}$; amplitude modulation index $m_{a}=0.78$

IEE Proc.-Electr. Power Appl., Vol. 142, No. I, January 1995 
Regulated DC link voltage $=400 \mathrm{~V}$; voltage ripple $=3$ V

Substituting these parameters into eqns. 5 and 11 , we can obtain:

$m_{5}=67$ or switching frequency $=4 \mathrm{kHz}$ and DC link capacitance $C=2200 \mu \mathrm{F}$ (voltage rating $>400 \mathrm{~V}$ ).

Shown in Fig. 11A are the three-phase input currents and the current in the source neutral line. By inspecting Fig. $11 \mathrm{~A}$ we can see that three-phase currents are fundamental sinewaves superimposed with high order harmonics.

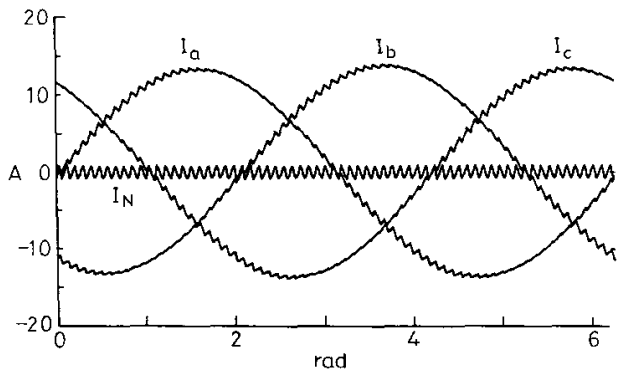

Fig. 11A Three-phase source and neutral currents

The neutral currents are compressed to a limited level and only with switching frequency ripple. The harmonics of the three-phase input currents are gathered around the multiple of switching frequency and the THD is 3.34\% well within the standards. Compared to a typical nonlinear load composed of three single phase diode rectifiers, which bears significant harmonics in both source and neutral currents (principally third harmonic), much lower THD is obtained. Input current of the phase A diode bridge is shown in Fig. 11B and the neutral current of

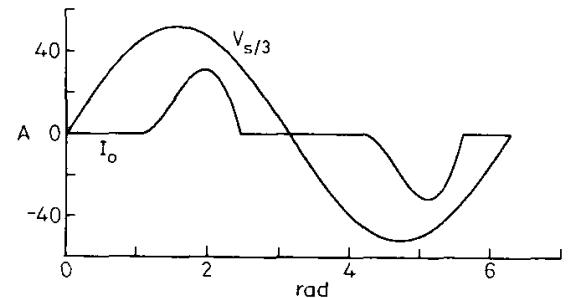

Fig. 11B Phase-A load curren

loads is shown in Fig. 11C. Here the load resistance is $20 \Omega$ per phase. By studying the harmonic contents in Figs. 11D and E, it can be found that the utility only supplies fundamental currents. Load peak current is about 2.5 times utility peak current. Also the level and harmonic contents of the utility neutral current has been

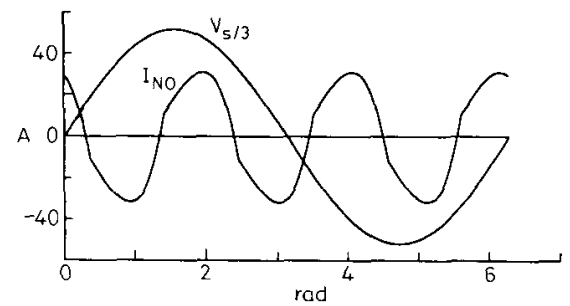

Fig. 11C Neutral currents of load

IEE Proc-Electr. Power Appl., Vol. 142, No. I, January 1995 considerably reduced. The regulated DC link voltage $(400 \mathrm{~V})$ is illustrated in Fig. 11F. The small $60 \mathrm{~Hz}$ ripple is the result of periodically changing the PWM control patterns with fundamental frequency.

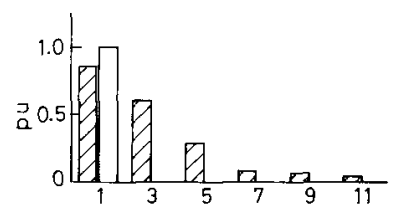

Fig. 11D Comparison of harmonic content of phase-A load current and phase-A source current

¿ load

source

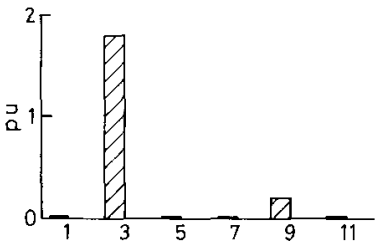

Fig. 11E Comparison of harmonic content of load neutral current and source neutral current

D load

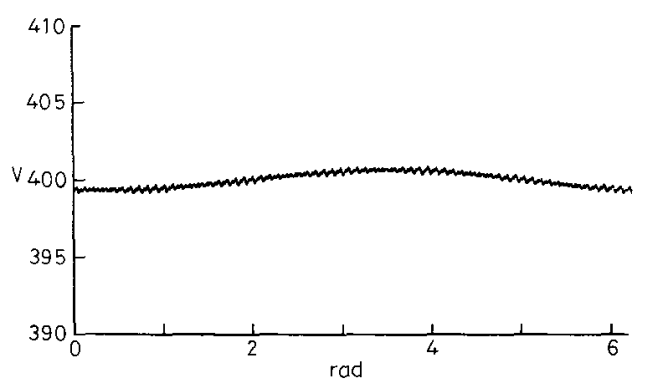

Fig. 11F Regulated DC-link voltage

If a switching. frequency of $20 \mathrm{kHz}\left(m_{f}=333\right)$ is adopted and the $\mathrm{AC}$ side impedance is a more typical value of $1 \Omega$, the THD of the source currents reduces further to $0.52 \%$. The harmonics are pushed to be above audible noises. This is illustrated in Fig. 12A. DC link

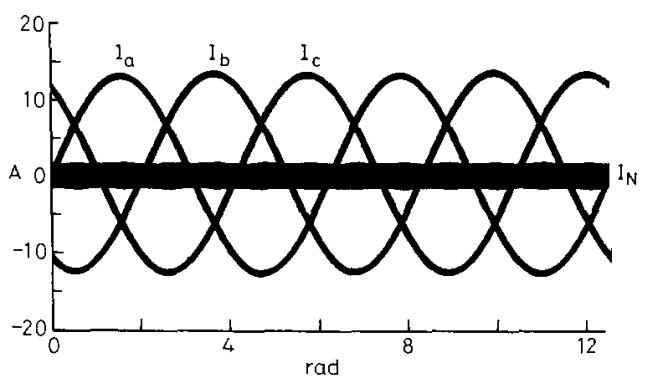

Fig. 12A Source and neutral currents

$m_{f}=333$

capacitors of smaller values reduce the size, weight and cost of the elements. In Fig. 12B, the capacitances are reduced to $560 \mu \mathrm{F}$. Though the ripple amplitude increases, it is still a very small portion (about $3 \mathrm{~V}$ peakto-peak) of the DC link voltages. We can see that the 
voltages of the two capacitors are almost identical. Thus the voltage imbalance problem encountered in half

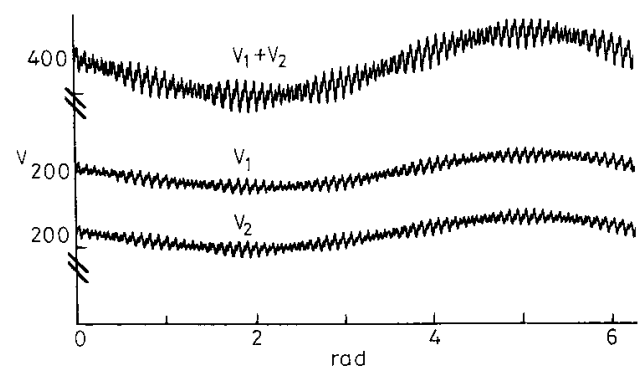

Fig. 128 DC link voltages of upper $\left(V_{1}\right)$ and lower $\left(V_{2}\right)$ capacitors

bridge schemes can be eliminated. Depicted in Fig. 13 is the phase A source current with $10 \%$ third harmonic distortion in source voltage. Even under the distorted source voltage, input current still remains neary sinusoidal.

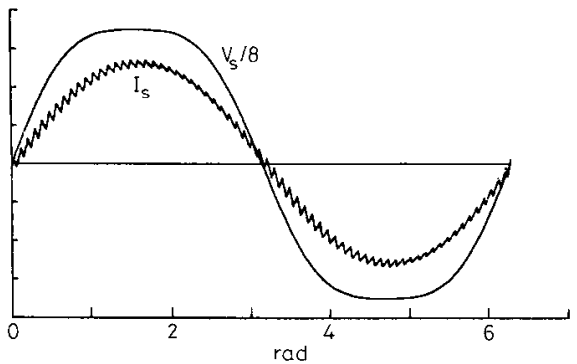

Fig. 13 Source current under distorted source voltage

As for the inverter, by programming the three-phase PWM control patterns with compensation on voltage ripple and dead times as discussed earlier, AC outputs without distortion can be achieved. Simulations have been performed on the system with $10 \% 120 \mathrm{~Hz}$ ripple superimposed on the DC link voltages and $m_{a}=0.78$. Shown in Figs. 14A and $B$ are the normalised illustrations of unfiltered phase A AC output and its spectrum. From Fig. 14B, a low-order (third) harmonic is present.

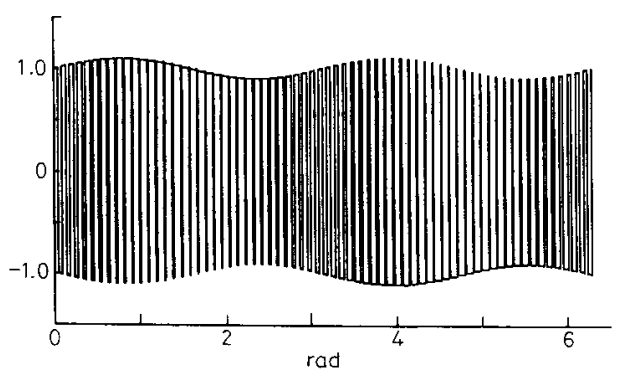

Fig. 14A Normalised AC output without compensation

This will make the output filtering difficult and impractical. As a comparison, the normalised phase A AC output and spectrum with compensation are depicted in Figs. 14C and D. The differences between Figs. 14A and Fig. $14 \mathrm{C}$ are not obvious since the compensation is revealed in the high frequency modulation function. However, in Fig. 14D the third-order harmonic is reduced greatly. By filtering out the harmomics which are multiples of the switching frequency, qualified $\mathrm{AC}$ outputs can be supplied to the loads.

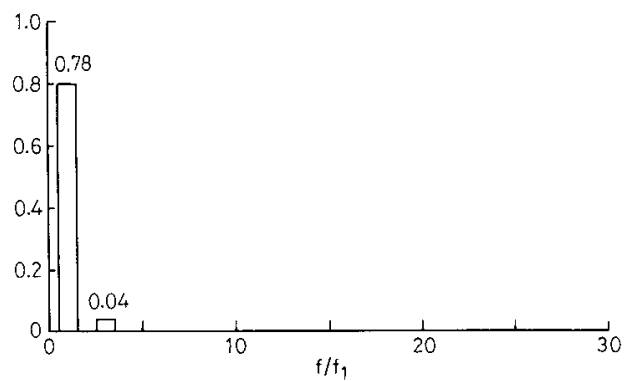

Fig. 14B Normalised spectrum of Fig. $14 \mathrm{~A}$

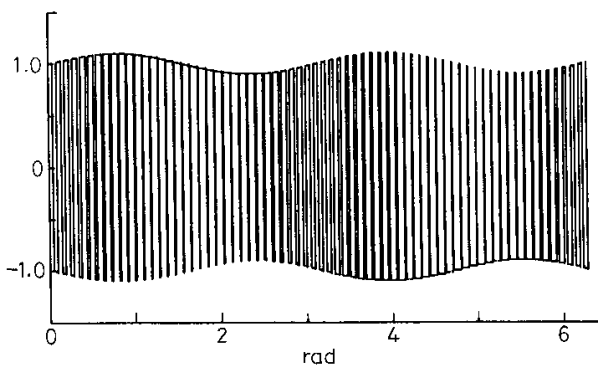

Fig. 14C Normalised AC output with compensation

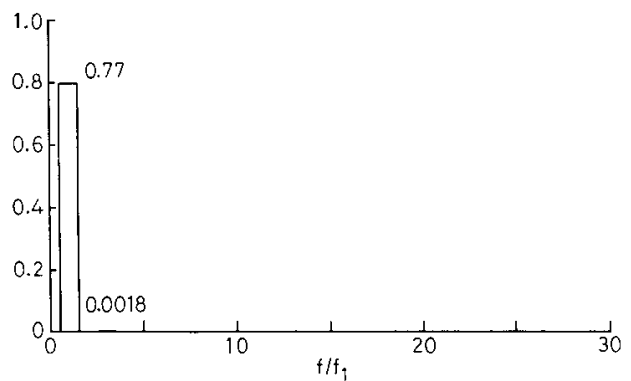

Fig. 14D Normalised spectrum of Fig. 14C

Illustrated in Fig. 15 is the experimental SMR phase A source current under voltage mode control. The source voltage ( $50 \mathrm{~V}$ RMS, $60 \mathrm{~Hz}$ ) is supplied by an AC power

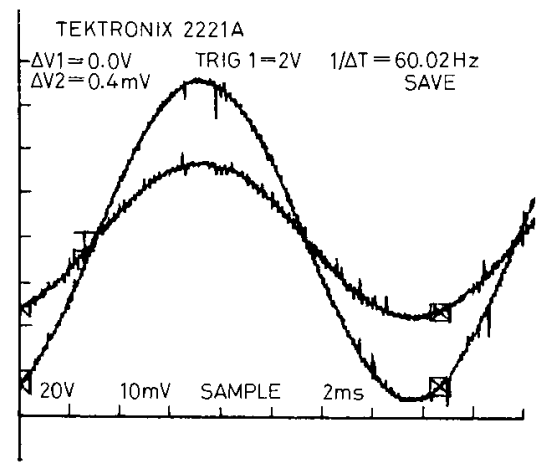

Fig. 15 Phase-A voltage and current

$20 \mathrm{~V} / \mathrm{div} ., 1 \mathrm{~A} / \mathrm{div}$

IEE Proc.-Electr. Power Appl., Vol. 142, No. I, January 1995 
supply. Input inductance and output capacitance are $2.6 \mathrm{mH}$ and $1150 \mu \mathrm{F}$, respectively. Switching frequency is $50 \mathrm{kHz}$ and $667 \Omega /$ phase loads are used. Output DC voltage is $400 \mathrm{~V}$. Shown in Fig. 16 are the SPWM control

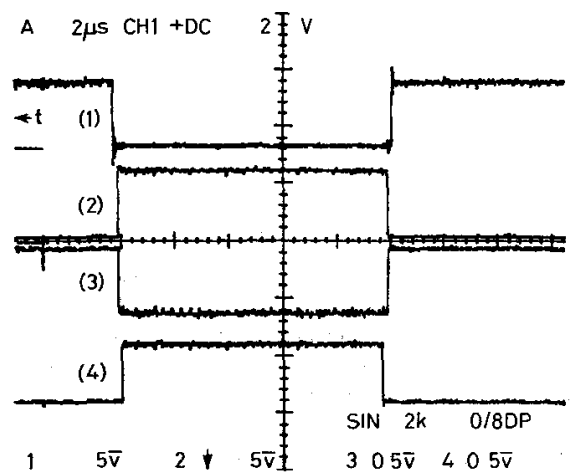

Fig. 16 Control signals for inverter switches with dead time compensation

signals fed to the inverter switches. (1) and (2) are for the lower and upper switches, respectively, when load current is positve. (3) and (4) are for the lower and upper switches, respectively, when load current is negative. We can see that (2) and (3) are the same as the original control signals, while (1) and (4) advance their turn offs and delay their turn ons to compensate the dead time degradation.

\section{Conclusions}

A new AC line conditioner has been presented in this paper for three-phase four wire applications. The aim of sinusoidal input currents and reduced level of neutral line current are achieved. Also a high quality AC output voltage is obtained regardless of DC link voltage ripples and dead times. The feasibility of voltage mode control for SMRs is proven. The degradation effects of nonlinear or unmatched loads can be separated from the power distribution system. Simulations show safisfactory performances of the proposed line conditioner.

With the expoditious progresses in semiconductor, high power rating and fast speed power switches such as GTOs and IGBTs, are now available. The proposed AC line conditioner can be implemented by utilising these switches and applied to any configuration of loads connected to three-phase four wire distribution systems.

\section{References}

1 MOHAN, N.: 'A novel approach to minimize line-current harmonics in interfacing power electronics equipment with 3-phase utility system'. IEEE summer power meeting, Seattle, WA, paper 92 SM 498-6 PWRD, 1992

2 OOI BT SALMON, JC DIXON, JW and KULKARNI A B 'A three-phase controlled current PWM convertor with leading power factor', IEEE Trans., 1987, IA-23, (6), pp. 78-84

3 MALESANI, L., and TENTI, P.: 'Three-phase AC/DC PWM convertor with sinusoidal $A C$ currents and minimum filter requirements', IEEE Trans., 1987, LA-23, (1); pp. 71-77

4 DIXON, J.W., and OOI, B.T.: 'Indirect current control of a unity power factor sinusoidal current boost type threo-phase rectifier', IEEE Trans. 1988, 1E-35, (4), pp. 508-515

5 QUINN, C.A., MOHAN, N., and MEHTA, H.: 'A four-wire, QUINN, C.A., MOHAN, N., and MEHTA, H.: 'A four-wire,
current-controlled convertor provides harmonic neutralization in three-phase, four-wire systems'. IEEE applied power electronics conference, 1993, pp. 841-846

6 MANIAS, S., ZIOGAS, P.D., and OLIVIER, G.: 'An AC-to-DC convertor with improved input power factor and high power density', IEEE Trans., 1988, IA-35, (4), pp. 508-515

7 LO, Y.K., CHEN, C.L. LIN, J.S., and WU, J.Y.: 'A new highperformance AC-to-AC conversion system'. 19th annual conference of IEEE industry electronics, 1993, pp. 824-829

8 . ENJETI, P.N., and SHIREEN, W.: 'A new technique to reject DC-link voltage ripple for inverters operating on programmed PWM waveforms', IEEE Trans., 1992, PE-7, (1), pp. 171-180

9 LEE, J.-Y, and SUN, Y.-Y: 'Adaptive harmonic control in PWM inverters with fluctuating input voltage', IEEE Trans., 1986, IE-33, (3), pp. 92-98

10 CLOSE, P.R., and EVANS, P.D.: 'Harmonic distortion in PWM inverter output waveform', IEE Proc. B, 1987, 134, (4), pp. 224-231

11 DODSIN, R.C., EVANS, P.D. YAZDI, H.T., and HARLEY, S.C. Compensating for dead time degradation of $\mathrm{PWM}$ inverter waveforms', IEE Proc. B, 1990, 137, (2), pp. 73-81

12 MOHAN, N, UNDELAND, T, and ROBBINS W.P.: 'Power electronics: convertors, applications and design' (John Wiley \& Sons, 1989), $667 \mathrm{pp}$ 